\title{
Effects of air pressure changes on gamma linear attenuation coefficient in the air
}

\author{
Wandi Wantoro, Suryasatriya Trihandaru*, Alvama Pattiserlihun \\ Physics Department, Faculty of Science and Mathematics, Universitas Kristen Satya Wacana, \\ Jl. Diponegoro 52-60 Salatiga 50711 Jawa Tengah, Indonesia
}

\begin{abstract}
The measurements of gamma linear attenuation coefficient in the air at variance air pressure has been done. The measurements were performed to determine the effects of air pressure changes on gamma linear attenuation coefficient in the air. The measurements were used Co60 as the gamma radiation source and LND 72 Geiger-Muller as the radiation detector in a room with $18^{\circ} \mathrm{C}$ room temperature and $68 \%$ air humidity. The linear attenuation coefficient value was calculated according to Lambert-Beer law. From the measurement, we obtained the attenuated gamma intensity in the air at air pressure variation. The unattenuated gamma intensity was determined by making a linear fit function of the attenuated gamma intensity data. From the calculation, It was found that the value of gamma linear attenuation coefficient in the air increases with the increasing of air pressure.
\end{abstract}

Keywords: air pressure, gamma ray, linear attenuation coefficient

Received: August 6, 2017; Accepted: September 15, 2017; Published online: October 31, 2017

*Corresponding author: suryasatriya@staff.uksw.edu

Citation: Wantoro, W., Trihandaru, S., \& Pattiserlihun, A. (2017). Effects of air pressure changes on gamma linear attenuation coefficient in the air. Journal of Science and Science Education, 1(2), 55-61.

\section{Introduction}

Nowadays nuclear radiation technology is used in a variety of different fields such as nuclear power stations, particle accelerators, medical hospitals and etc. (USNRC, 2017). Nuclear radiation can emit high energy but can not felt directly by human senses and thus the use of nuclear radiation must be arranged and supervised according to IAEA on his book entitled "radiation protection and safety of radiation sources: international basic safety standards" (IAEA, 2014).

In radiation protection activity is known by linear attenuation coefficient. Linear attenuation coefficient has defined as the probability of a photon interacting with a material per unit path length (Akkurt, 2012). The value of linear attenuation coefficient has shown how much photon fraction through an absorber.

Air is a mixture of many gases that surrounds the earth (Prayudi, 2011). The condition of air has referred to temperature, humidity, and air pressure. Air pressure is the force exerted by the weight of the air. The value of air pressure is affected by air temperature and moisture (Pressure, 2013). Air also a material which interacts with photon radiation, so air has the value of linear attenuation coefficient.

There are several studies that gamma linear attenuation coefficient has measured in some materials such as alloy, concrete, air, ect (Akkurt, 2012; Singh, 2013; Singh, 2015; Elmahroug, 2015; Sharaf, 2013; De Figueiredo, 2015). In this paper, we measure the gamma linear attenuation coefficient in 
Wantoro, Trihandaru, \& Pattiserlihun: Effects of air pressure changes on gamma linear attenuation coefficient in the air

the air at variance air pressure. The result is used to determine the effects of air pressure changes on gamma linear attenuation coefficient in the air.

\section{Materials and Methods}

\subsection{Gamma intensity measurement}

Gamma intensity measurement was done by penetrating gamma rays through the materials (Foldiak, 1986). The gamma rays through the absorber which the gamma source was placed opposite sides with the radiation detector on the same axis (Buyuk, 2014). The radiation detector then counted the gamma ray which comes from the source. Gamma intensity measurement was done using Co-60 as gamma radiation source and LND 72 Geiger-Muller as a radiation detector. The radiation detector counting was performed using Logger Pro software (Logger Pro, 2017). Figure 1 shows the schematic view of gamma intensity.

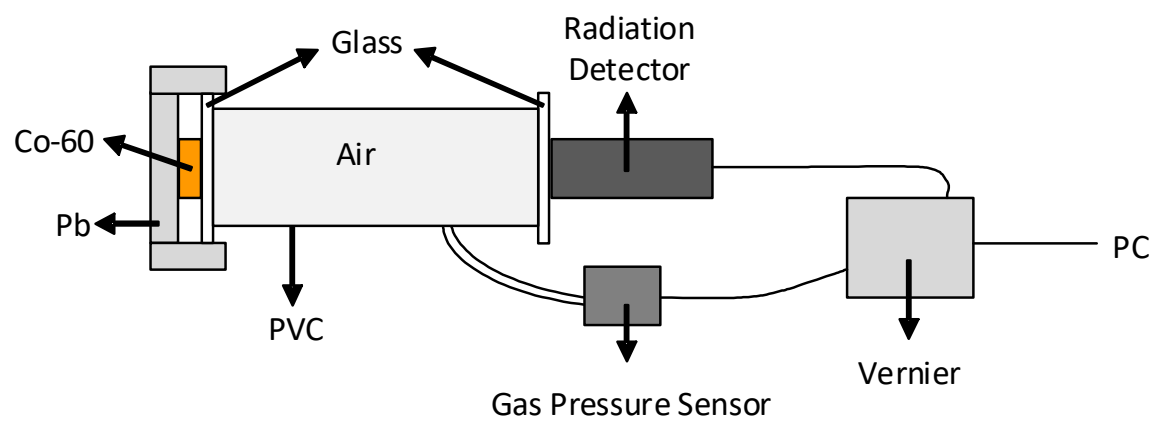

Figure 1. The schematic view of gamma intensity measurement.

Gamma intensity measurements were made at a distance or thickness variation absorber $5 \mathrm{~cm}, 10$ $\mathrm{cm}, 15 \mathrm{~cm}$ and $20 \mathrm{~cm}$. The measurements were performed in a room with $18^{\circ} \mathrm{C}$ temperature and $68 \%$ air humidity. The measurements were made at an air pressure variation $25 \times 10^{3} \mathrm{~Pa}$ to $190 \times$ $10^{3} \mathrm{~Pa}$ with the variation range of air pressure $5 \times 10^{3} \mathrm{~Pa}$. In each air pressure variation, the radiation detector was counted the gamma ray in $60 \mathrm{~s}$ and $120 \mathrm{~s}$ then it repeated six times.

\subsection{Calculation of linear attenuation coefficient}

The calculation of linear attenuation coefficient of gamma radiation in the air has accorded to Lambert-Beer law (Akurt, 2013):

$$
I(x)=I_{0} e^{-\mu x},
$$

where $I(x)$ was the attenuated gamma intensity, $I_{0}$ was the unattenuated gamma intensity, $\mu$ was the linear attenuation coefficient and $x$ was the thickness of absorber. By took the logarithm of both sides of Eq. (1), we have calculated the value of the linear attenuation coefficient (Singh, 2002; Sharaf, 2013):

$$
\mu=\frac{1}{x} \ln \frac{I_{0}}{I(x)},
$$




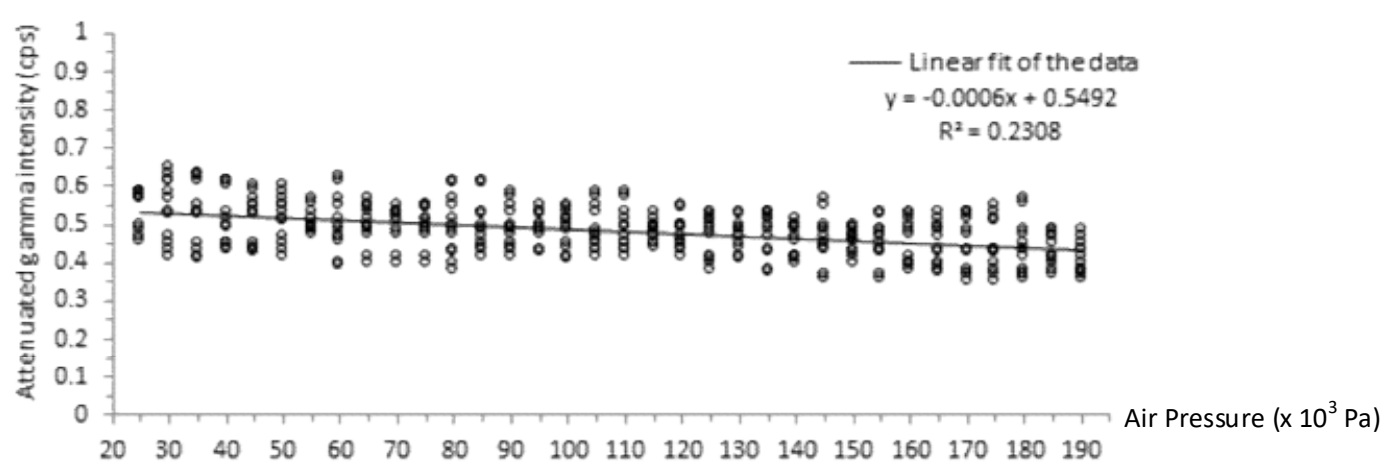

(a)

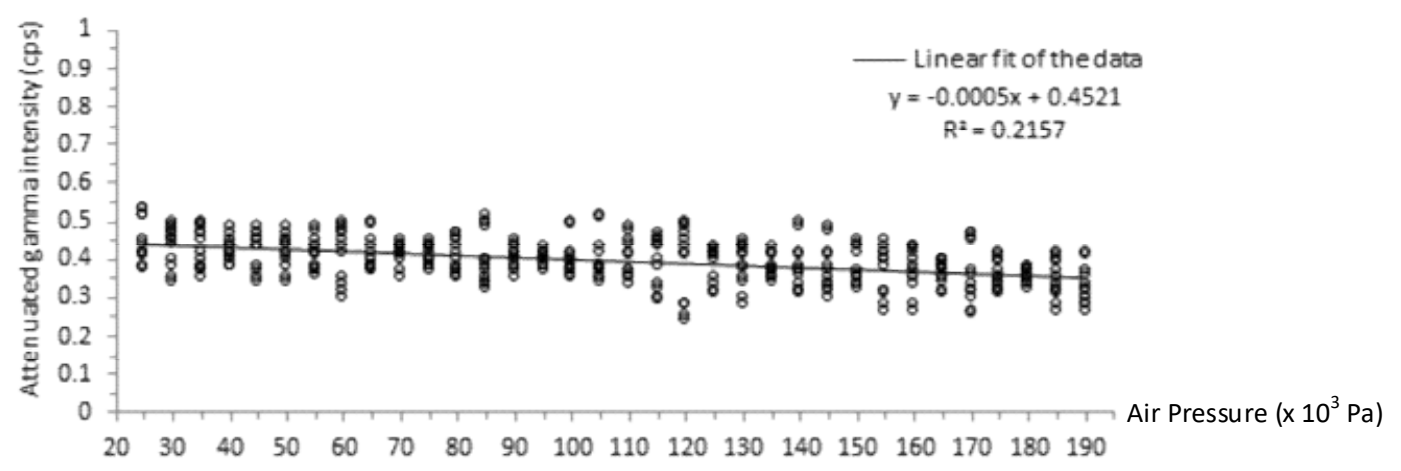

(b)

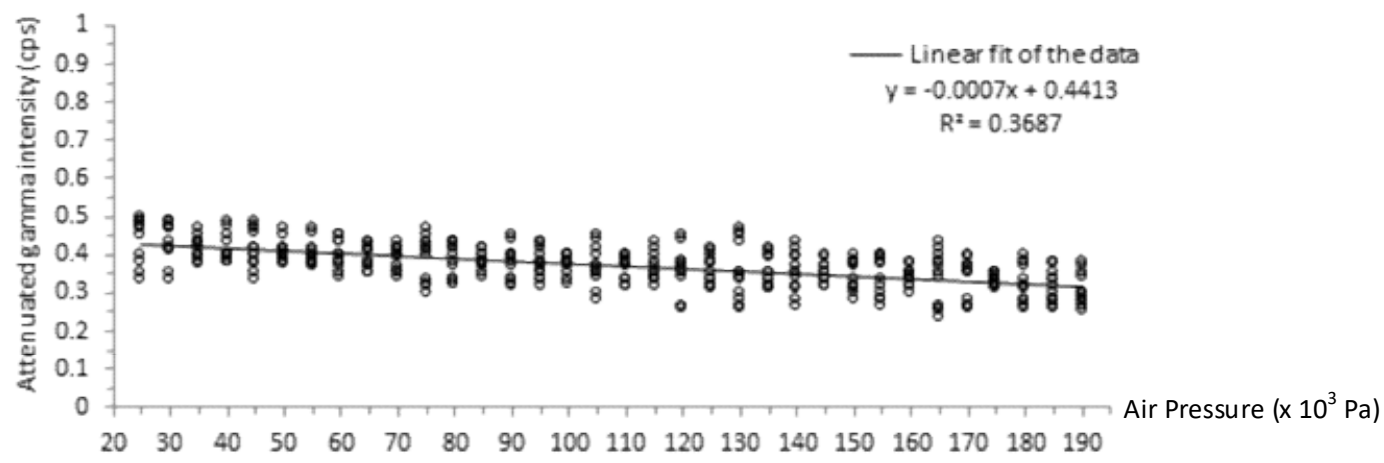

(c)

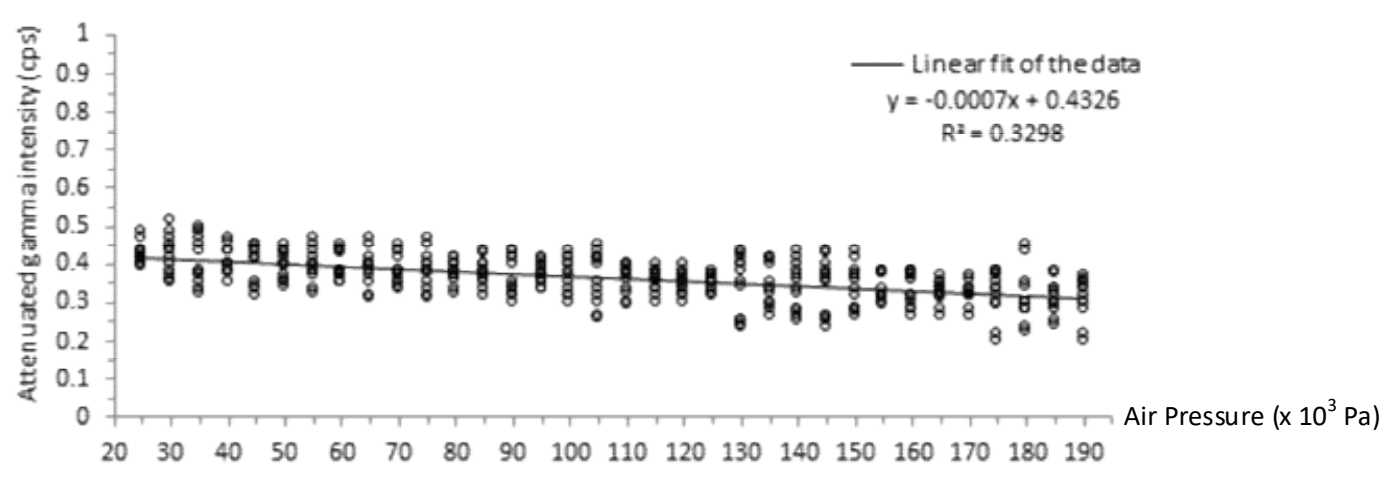

(d)

Figure 2. Attenuated gamma intensity. (a) $5 \mathrm{~cm}$ thicknes absorber, (b) $10 \mathrm{~cm}$ thicknes absorber, (c) $15 \mathrm{~cm}$ thicknes absorber, (d) $20 \mathrm{~cm}$ thicknes absorber. 
Wantoro, Trihandaru, \& Pattiserlihun: Effects of air pressure changes on gamma linear attenuation coefficient in the air

\section{Results and Discussion}

The results of gamma intensity measurements on each air pressure variation can be seen in Figure 2. From the data of Figure 2, was made a linear fit to determine the value of unattenuated gamma intensity.

Table 1 shows the value of unattenuated gamma intensity at each absorber thickness. The value of unattenuated gamma intensity obtained from the linear fit function:

$$
I(x)=a P+I_{0} \text {. }
$$

Table 1. The Value of unattenuated gamma intensity.

\begin{tabular}{cc}
\hline $\begin{array}{c}\text { Absorber thickness } \\
\text { (cm) }\end{array}$ & $\begin{array}{c}\text { Unatenuated gamma intensity } \\
\text { (cps) }\end{array}$ \\
\hline 5 & 0.549212185 \\
10 & 0.452114528 \\
15 & 0.441340612 \\
20 & 0.432642072 \\
\hline
\end{tabular}

The value of linear attenuation coefficient was calculated by using Eq. (2) as illustrated in Figure 3. Figure 3 shows that the value of linear attenuation coefficient in air increases with the increasing of air pressure. It is because of the value of linear attenuation coefficient in the air is affected by the value of air density (De Figueiredo, 2011). The value of air density itself is affected by many factors that one of them is air pressure changing. The value of air density is increased with the increasing of air pressure (Davis, 1992).

From the data of Figure 3, the effect of air pressure changes on gamma linear attenuation coefficient in the air was obtained. The effect of air pressure changes on gamma linear attenuation coefficient in the air is determined by made a linear regression of the data so the corelation function of air pressure changes on gamma linear attenuation coefficient in the air can be presented as:

$$
\mu=a P+\mu_{0},
$$

where $\mu$ was the linear attenuation coefficient at $\mathrm{P}$ air pressure value, $\mathrm{P}$ was the value of air pressure, $\mu_{0}$ was the linear attenuation coefficient at 0 air pressure, and $a$ was the effect of air pressure changes on gamma linear attenuation coefficient. Table 2 shows the correlation function of air pressure changes on gamma linear attenuation coefficient in the air at each absorber thickness variation.

Table 2. The correlation function of air pressure changes on gamma linear attenuation coefficient in the air.

\begin{tabular}{cc}
\hline $\begin{array}{c}\text { Absorber thickness } \\
(\mathbf{c m})\end{array}$ & Function \\
\hline 5 & $y=2.56 \cdot 10^{-4} x-0.00143$ \\
10 & $y=1.37 \cdot 10^{-4} x-0.00088$ \\
15 & $y=1.17 \cdot 10^{-4} x-0.00082$ \\
20 & $y=8.98 \cdot 10^{-5} x-0.00064$ \\
\hline
\end{tabular}

From the data in Table 2, the value of linear attenuation coefficient was calculated. The calculated value of linear attenuation coefficient then compared with the linear attenuation coefficient value from the data of Figure 3. 


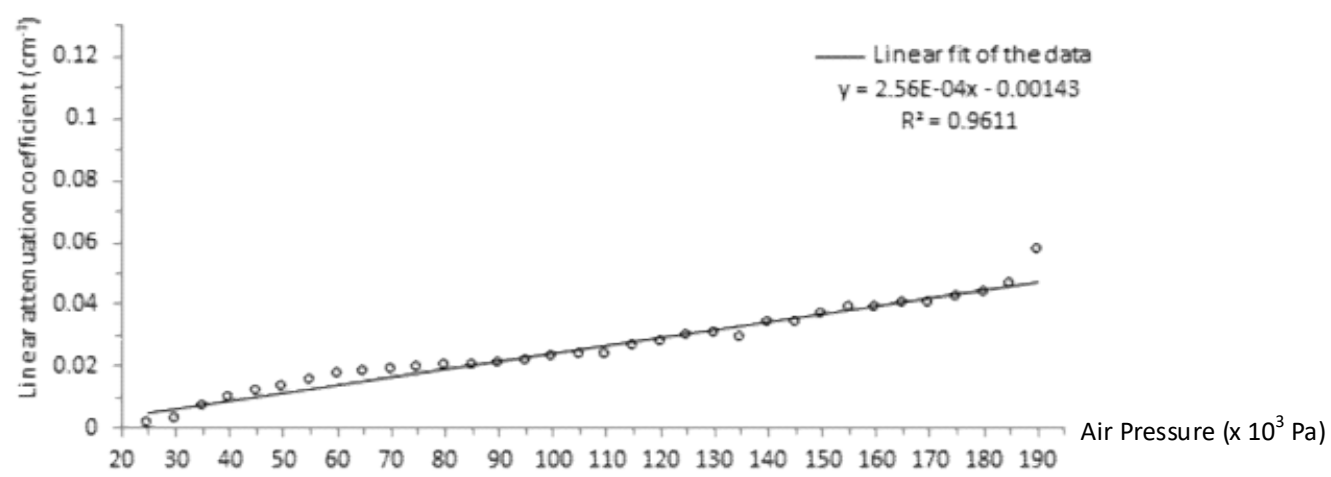

(a)

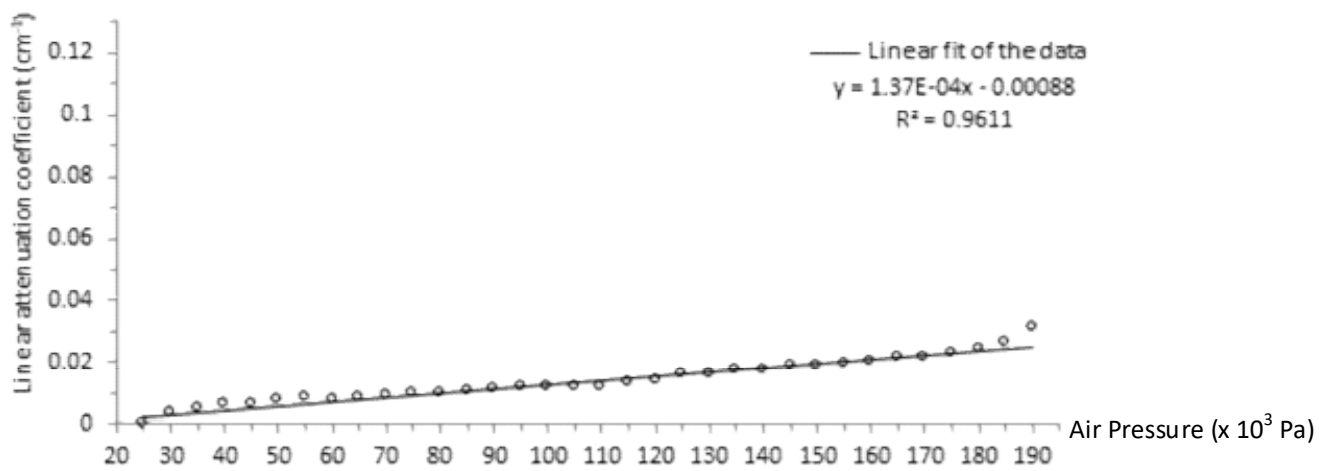

(b)

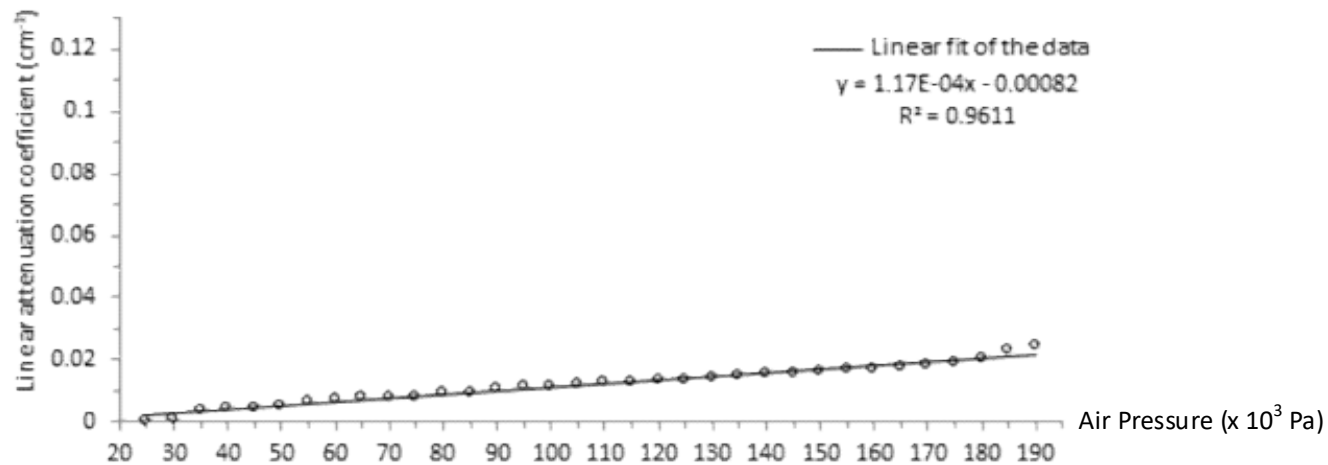

(c)

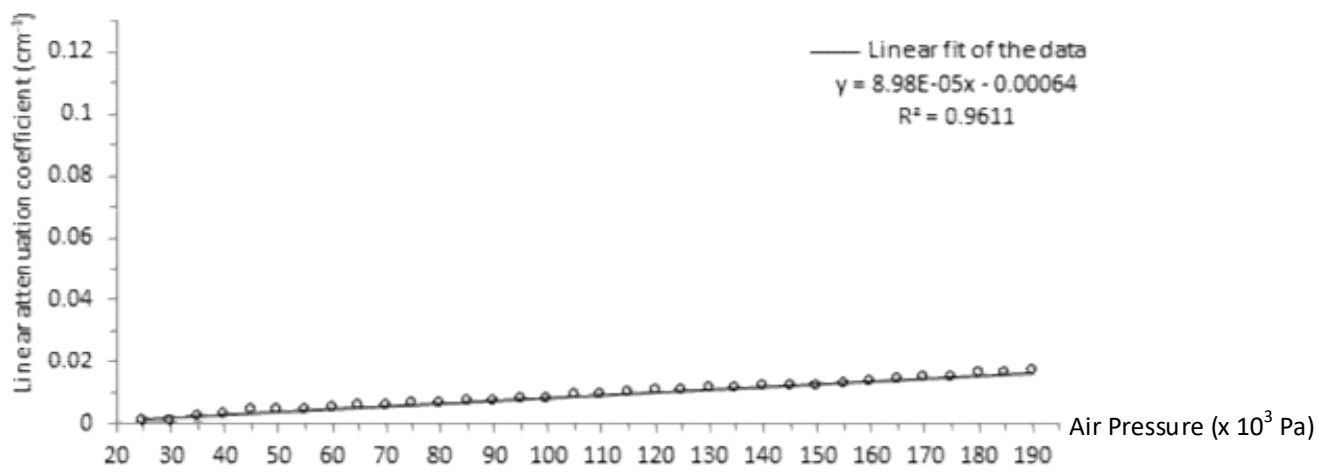

(d)

Figure 3. The value of linear attenuation coefficient at each air pressure variation. (a) $5 \mathrm{~cm}$ thicknes absorber, (b) $10 \mathrm{~cm}$ thicknes absorber, (c) $15 \mathrm{~cm}$ thicknes absorber, (d) $20 \mathrm{~cm}$ thicknes absorber. 
Wantoro, Trihandaru, \& Pattiserlihun: Effects of air pressure changes on gamma linear attenuation coefficient in the air

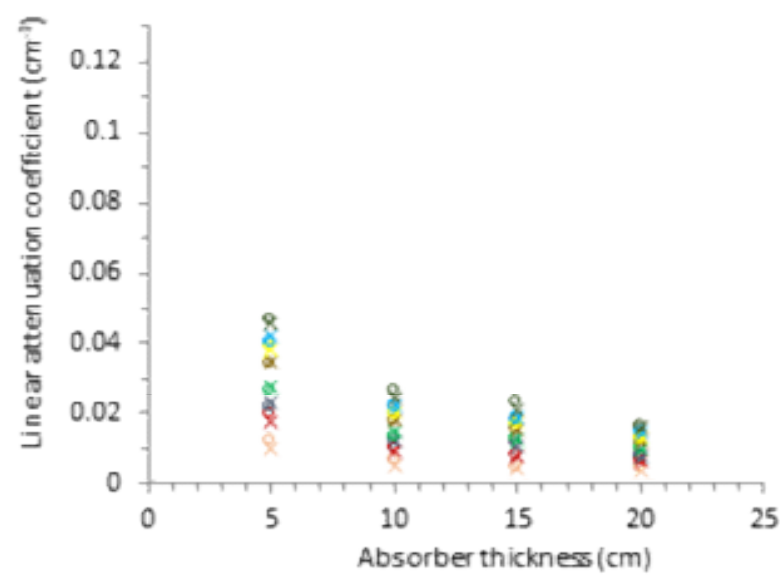

Figure 4. The linear attenuation coefficient, (o) value from the data, $(x)$ calculated value according to linear function at each absorber thickness, $(-)$ at $45 \times 10^{3} \mathrm{~Pa}$, $(\square)$ at $75 \times 10^{3} \mathrm{~Pa},(\square)$ at $95 \times 10^{3} \mathrm{~Pa},(\square)$ at $115 \times 10^{3} \mathrm{~Pa}$, $(\square)$ at $140 \times 10^{3} \mathrm{~Pa},(-)$ at $155 \times 10^{3} \mathrm{~Pa},(\square)$ at $170 \times 10^{3}$ $\mathrm{Pa},(\square)$ at $185 \times 10^{3} \mathrm{~Pa}$.

Figure 4 shows the comparison of the calculated linear attenuation coefficient value with the linear attenuation coefficient value from the data. It is found that the calculated value of linear attenuation coefficient has a small difference with the linear attenuation coefficient value from the data. Figure 4 shows that the linear attenuation value in the air decreases with absorber thickness increases in a logarithmic function.

\section{Conclusion and Remarks}

In this paper, the gamma linear attenuation coefficient in the air at air pressure variation was measured. The measurements are performed to determine the effect of air pressure changes on gamma linear attenuation coefficient in the air. The measurements were used Co-60 as the gamma radiation source and LND 72 Geiger-Muller as the radiation detector in a room with $18^{\circ} \mathrm{C}$ room temperature and $68 \%$ air humidity. From the measurement, we obtained the attenuated gamma intensity in the air at air pressure variation. The unattenuated gamma intensity was determined by making a linear fit function of the attenuated gamma intensity data. From the calculation, It was found that the value of gamma linear attenuation coefficient in the air increases with the increasing of air pressure.

\section{References}

De Figueiredo, M. T. T., Guimarães, M. C., \& Da Silva, T. A. (2011, October). The influence of air humidity on the determination of the half-value layer of low energy $x$-ray reference radiation. Paper presented at 2011 International Nuclear Atlantic Conference, Belo Horizonte, Brazil.

Buyuk, B., \& Tugrul, A.B. (2014). An investigation on gamma attenuation behaviour of titanium diboride reinforced boron carbide-silicon carbide composites. Radiation Physics and Chemistry, 97, 354-359

Akkurt, I., \& El-Khayatt, A. M. (2013). The effect of barite proportion on neutron and gamma-ray shielding. Annals of Nuclear Energy, 51, 5-9.

Sharaf, J. M., \& Hamideen, M. S. (2013). Photon attenuation coefficients and shielding effects of Jordanian building materials. Annals of Nuclear Energy, 62, 50-56. 
Földiak, G. (1986). Industrial application of radioisotopes. Amsterdam: Elsevier.

Singh, K. (2002). Gamma-ray attenuation coefficients in bismuth borate glasses. Nuclear Instruments and Methods in Physics Research, B 194, 1-6.

Davis, R. S. (1992). Equation for the determination of the density of moist air. Metrologia, 29, 67-70.

Vernier Software \& Technology. (2017). Logger Pro. Retrieved from https://www.vernier.com/products/software/lp/

IAEA (2014). Radiation protection and safety of radiation sources: international basic safety standards. Viena: Austria.

Akkurt, I., Altindag, R., Gunoglu, K., \& Sarıkaya, H. (2012). Photon attenuation coefficients of concrete including marble aggregates. Annals of Nuclear Energy, 43, 56-60.

USNRC (2017). Radiation All Around Us. Retrieved from https://www.nrc.gov/about-nrc/radiation/aroundus/uses-radiation.html

Prayudi, T., \& Susanto, J. P. (2011). Kualitas debu dalam udara sebagai dampak industri pengecoran logam ceper. Jurnal Teknologi Lingkungan, 2, 168-174.

Singh, V. P., \& Badiger, N. M. (2013). Gamma ray and neutron shielding properties of some alloy materials. Annals of Nuclear Energy, 64, 301-310.

Singh, V. P., Medhat, M. E., \& Badiger, N. M. (2015). Photon energy absorption coefficients for nuclear track detector susing Geant4 Monte Carlo simulation. Radiation Physics and Chemistry, 106, 83-87.

Elmahroug, Y., Tellili, B., \& Souga, C. (2015). Determination of total mass attenuation coefficients, effective atomic numbers and electron densities for different shielding materials. Annals of Nuclear Energy, 75, $268-274$. 